Acta Hispanica (2015) 20: 91-104

\title{
SIGNIFICADOS DE LA MUERTE E INMIGRACIÓN EN LA PELÍCULA BIUTIFUL
}

\author{
Olivia N. Petrescu
}

Universidad Babeş-Bolyai

Resumen: La presente ponencia procede a un análisis hermenéutico de la narrativa que subyace en la película Biutiful, dirigida por Alejandro González Iñárritu en el año 2010, con el propósito de examinar los destinos de los personajes, sometidos a la muerte, a la pobreza, a la emigración y al trapicheo de todo tipo, con el telón de fondo de una Barcelona sórdida y marginal. A pesar de ser una representación filmica de una realidad dura y angustiosa -con muchos vínculos intertextuales que remiten a la narrativa fantástica-, la película realiza una estremecedora introspección sobre lo que significa el amor y la culpa, tener hijos y vivir bajo la sombra de la muerte, desde diferentes perspectivas que superan los límites espacio-temporales, étnicos o espirituales.Todo ello servirá para enfocar nuestro estudio hacia una interpretación cultural del binomio vidamuerte, desde la encrucijada de los tres destinos y comunidades tan diferentes: chinos, senegaleses y españoles, imaginada por el director mexicano.

Palabras clave: Biutiful, muerte, inmigración, hermenéutica, intertextualidad

\begin{abstract}
Starting from the hermeneutics of the plot identifiable in the movie Biutiful, directed by the Mexican Alejandro González Iñárritu in 2010, our study aims to analyse the multicultural connections among the characters, in terms of their tragic destinies, of the death, illegal immigration and poverty in an unusual framework as it is that of a sordid and marginal Barcelona.Even if the story concerns only a film, one could embody multiple intertextual references which allude to fantasy literature. Besides, the harsh reality and the anxieties experienced by the main protagonist establish a credible insight of some real ethnic, social and spiritual phenomena, specific for XXI century Europe, but also universal for all ages of humanity. From this perspective, our exegesis is meant to be a cultural interpretation of the life-death significance, as perceived through three crisscrossing communities in the motion picture: the Spanish, Chinese, and Senegalese communities, which metaphorically represent three very different continents and cultures.
\end{abstract}

Key-words: Biutiful, death, inmigration, hermeneutics, intertextuality

"Rien ne nous flatte tant que l'obsession de la mort; l'obsession, et non la mort"1

${ }^{1}$ Emil CIORAN, Syllogismes de l'amertume, Paris, Gallimard, 1952, 22. 
Significados de la muerte e inmigración en la película Biutiful

\section{A modo de introducción}

Cualquier análisis hermenéutico construido en torno a los posibles significados de una película apunta, a primera vista, a un proceso relativamente fácil, teniendo en cuenta la duración limitada de la experiencia visual y la concisión implícita del guión. El director mexicano Alejandro González Iñárritu se ha hecho famoso por su estilo, que abunda en rupturas y fragmentaciones y que se aprecia en guiones escritos junto con Guillermo Arriaga y materializados en películas muy valoradas como Amores perros (2000), 21 Grams (2003) y Babel (2000) ${ }^{2}$. En cambio, Biutiful (2010) plantea un largometraje más ordenado en ritmo y musicalidad, con menos nervio en comparación con las películas anteriores, pero igual de profundo y polisemántico.

Consecuentemente, Biutiful revela desde el principio que se trata de historias sobre la muerte y sus múltiples caras, en una lucha desesperada por exceder los límites del yo. El ensayista rumano exiliado en Paris, Emil Cioran, avisaba ya desde sus escritos de juventud que, de hecho, lo que subyuga a la humanidad no es la muerte, sino su obsesión. Es verdad que la muerte humana encarna las inquietudes más estremecedoras de índole biológica, socioantropológica, filosófica, literaria, etc., según cada época y cada individuo. A pesar del carácter contradictorio y paradójico de la muerte, ya que representa un atributo universal de la existencia y, al mismo tiempo, su negación, la manera de revelarse individualmente es única. A este respecto, nos proponemos indagar cuáles son los protagonistas y el panorama sociocultural que otorgan el color final a las muertes en Biutiful y qué mecanismos intervienen para sustentar esa especie de poética de lo sórdido, de la emigración y de la enfermedad del siglo XXI.

\section{Debate al margen de la narrativa fílmica}

La película Biutiful gira en torno a un solo personaje central, cuya trágica historia arrastra los demás destinos secundarios. En una Barcelona contemporánea y marginal, el ambiente se vuelve cada más alienado y hostil a medida que aumenta la presencia de la muerte. Como género, nos situamos en la zona limítrofe entre la tragedia personal y el drama social, salpicado constantemente por el sombrío diario íntimo de una enfermedad terminal, así como por la situación desoladora de la inmigración ilegal en España. De hecho, la pregunta esencial que guía el hilo narrativo entero es la siguiente: ¿Qué pasa con una persona cuando sabe que va a morir? Esta clave retórica de la película, introducida por un poético preámbulo (que es, al mismo tiempo, epílogo), se mantendrá a lo largo de la narración, que sigue fielmente al pobre enfermo, a punto de perder su fuerza vital. Uxbal malvive de trabajillos, a veces ilegales, mientras intenta encontrar un relativo equilibrio entre la custodia de sus dos hijos pequeños y el apoyo dificultoso a su mujer, muy vulnerable. Entre el filo del trapicheo y la sombra de la muerte, este perfila un auténtico personaje fantástico que se columpia entre Borges y Macondo.

\footnotetext{
${ }^{2}$ Las tres películas han sido enmarcadas por la crítica en la Trilogía de la Muerte, tema predilecto del director mexicano.
}

92 | Acta Hispanica, Hungría 20: 91-104, 2015, ISSN: 1416-7263 
Iñárritu carga con un peso de fatalidad los hombros de este personaje, al que enfrenta con un abanico repugnante de vicios e instintos animales. Es más, posee el don de comunicarse con los espíritus de los recién fallecidos, aspecto que multiplica su responsabilidad social y complica sus problemas morales. A consecuencia de todo ello, su imagen se tambalea dramáticamente y el paso del tiempo pasado-presente-futuro se convierte en una larga experiencia tanatológica. En efecto, la trama empieza el día en que es diagnosticado de metástasis y, al enterarse de que apenas le quedan unos pocos meses hasta morir, todos sus actos persiguen encontrar la paz, preparar moralmente a sus hijos y tratar de cerrar sus asuntos pendientes. ¿Logrará conseguir la reconciliación consigo mismo o todo quedará en un intento fracasado? Antes de responder, merece la pena recordar la tremenda evolución de Uxbal, magistralmente retratada en la actuación de su intérprete, Javier Bardem. Se trata de un personaje muy coherente, pero lo que impresiona es la asombrosa metamorfosis que transmite al transcurso narrativo. Si bien pretende ser un individuo duro, firme y seguro de sí mismo, sabe repartir a la vez, esperanza y apoyo a los inmigrantes más pobres y necesitados. Como su oficio habitual consiste en tratar de proteger, con poco beneficio, las ventas ilegales de los inmigrantes africanos en la capital catalana, cree tener un acuerdo con la policía, pero le detienen una vez por haber defendido a un amigo senegalés. A partir de ahí, se lanza a una lucha contra la corrupción social y su propia corrupción interior. Atormentado por el universo mísero que le rodea, sufridor él mismo de la pobreza, de la explotación y de la degradación humana, además del cáncer que le merma fuerzas físicas cada día, el protagonista sí logra reconciliarse al final consigo mismo y con los demás, revelando su vigor emocional y solidez moral. Sin embargo, hay ciertos aspectos delicados en esta película, cuestiones que, al ser investigadas desde perspectivas diferentes, reales y ficcionales (declaraciones del director y de la crítica, hermenéutica propia y ajena) apuntan a múltiples interpretaciones sobre la inmigración, la pobreza y la enfermedad terminal.

Quizás la primera conexión con una historia filmica parecida sea la película Los olvidados (1950) de Luis Buñuel, en la que un español retrata la miseria mexicana, mientras que en Biutiful es un mexicano el que pone en tela de juicio, sesenta años después, una realidad que muchos europeos no están dispuestos a ver. De hecho, en una entrevistadebate con el escritor Jorge Volpi publicada en el periódico El País, Iñárritu confiesa que su reciente película "habla de la conquista de España por los inmigrantes", aludiendo a los ilegales invisibles de una ciudad que, aunque sea una de las más hermosas del mundo, también padece la enfermedad de la pobreza, de la droga y de la delincuencia, junto con sus habitantes más desamparados. ${ }^{3}$ Así pues, del núcleo básico constituido por Uxbal, el argumento entreteje concéntricamente una especie de red perversa, en la que están atrapados familiares, emigrantes y vecinos en un destino irreversible.

\footnotetext{
${ }^{3}$ http://elpais.com/diario/2010/12/03/cine/1291330801_850215.html
} 
En este panorama complejo, la migración, como tema social, resalta como un leit motiv en las películas del director mexicano. Lo que cambia en cada una de ellas es el marco existencial y las sociedades de acogida, ya que el mensaje en favor de la dignidad y la tolerancia parece ser siempre el mismo. Biutiful se desarrolla en una Barcelona, que bien podría sustituir a cualquier otro lugar del espacio comunitario europeo o del mundo, en los que el tratamiento social, laboral, y al fin de cuentas, humanitario, deja mucho por desear, como señaló Carlos Fuentes: "Chinos y senegaleses aquí, como mexicanos en California, turcos en Alemania, argelinos en Francia y, ayer apenas, trabajadores españoles en Francia, Inglaterra, Escandinavia. Biutiful toca aquí el gran problema irresuelto de la emigración. ¿Por qué, si en un mundo globalizado circulan sin trabas el dinero, los valores, las empresas, no puede circular el trabajo?"4

En la película, casi todos los personajes, vivos hasta el final o fallecidos en el transcurso de la película, son emigrantes o han tenido alguna relación con la emigración y con algún sueño fracasado sobre un El Dorado donde trabajar y vivir dignamente. Es más, el primer enlace lo establece el mismo padre de Uxbal, que había huido de la Guerra Civil española a México, donde falleció sin conocer a su hijo. A su vez, este se convierte en mediador entre los mundos periféricos barceloneses, cuyas comunidades más desfavorecidas quedan también ligadas por los mismos delitos. Por un lado, dos chinos homosexuales explotan cruelmente a sus compatriotas trabajadores, los cuales viven y duermen encerrados con sus familias en un sótano-bodega sin calefacción, ni la más mínima higiene. Su vida y su trabajo ilegal esclavizado resultan una triste y larga repetición de la pobreza y de la falsedad, en circunstancias casi inimaginables. A pesar de ello, hay ternura y compasión, expresadas admirablemente a través de Li, una niña mujer y su bebé recién nacido, víctimas que comparten los mismos espacios y condiciones. Por otro lado, el espacio de los africanos se reduce a las chozas donde se esconden amontonados por las noches, casi sin poder respirar, mientras pasan un día a día arriesgado en las calles céntricas, dedicados a la venta ilegal de productos chinos falsificados. Sin considerar los inmensos peligros que corren, tampoco su paga tan mísera, los senegaleses caen presos en el espantoso vaivén de la cárcel, de la venta de droga y de la engañosa realidad sin salida.

Bastará con afirmar que las dos comunidades extranjeras tratadas son de inmigrantes ilegales y se ubican en el argumento en función de su nudo referencial, o sea Uxbal, un español meridional, también desarraigado de algún modo en Cataluña. Además, la sensación general que rodea a estas personas es de brutalidad y violencia. Entre la multitud de escenas chocantes, se pueden mencionar dos entre los más inquietantes, las cuales reflejan graves consecuencias de la emigración mundializada. La primera es la muerte colectiva de los trabajadores chinos, hombres, mujeres y niños, asfixiados con gas en el sótano donde dormían enclaustrados. A pesar de ser un accidente, a Uxbal le toca parte de culpa, porque había sido él quien había comprado las pésimas estufas para

4 Carlos FUENTES, La Nación en http://blogsdelagente.com/ana-tosi/2011/02/09/carlosfuentes-nos-cuenta-una-pelicula-biutiful/ 
el desolador dormitorio-ataúd. A raíz del suceso trágico, su misión antes de morir se hace todavía más dolorosa. Al día siguiente, el mar arroja los cuerpos a la playa, sin turistas, ni bañistas: solo hay muertes sin nombre, sin razón.

La segunda escena muy conmovedora gira en torno a la actitud de Ige, la mujer de origen senegalés. Madre sin recursos, con el marido preso y sin mucha ilusión de encontrar su felicidad en tierras ibéricas, se ve confrontada a la elección moral y humana más difícil. Así, cuando se acerca su fin, Uxbal le entrega todo su dinero para que se quede en casa y siga cuidando de sus hijos. Entre la duda de irse a su patria y un futuro incierto en Cataluña, la película no da una respuesta cerrada, pero la piedad de la mujer se presenta como sublime.

La pregunta al hilo de este tema es si realmente el director logra ofrecer una imagen general honesta de la inmigración en España o, al contrario, si su película explota una actitud xenófoba y discriminatoria al respecto. En este sentido, Jennifer A. Patterson ${ }^{5}$ y otros estudiosos sostienen que Biutiful agudiza la mala percepción de la inmigración ilegal, en general, y senegalesa, en especial. Esta actitud, advierten ellos, en tiempos de crisis y nacionalismos contundentes, podría acabar en posiciones muy arriesgadas, aunque las organizaciones internacionales traten de proteger los derechos humanos. Y añaden como indicio de ello el hecho de que muchas veces la prensa autóctona aprovecha temas sensacionalistas para deformar gravemente las circunstancias reales, en vez de abrir caminos hacia verdaderas soluciones de la cuestión étnica, con miras a la inclusión social y moral.

En lo que nos concierne, creemos que toda obra artística está "libre de cargos" a la hora de usar cualquier elemento ficcional sin cuestionarlo, siempre que el público no saque su interpretación fuera del contexto, y esto no suele ocurrir al tratarse de una película social, en la que tanto los escenarios como los personajes son reales. Por consiguiente, la narrativa sería completa si sumara a la trama una voz legítima que hablase en nombre de la comunidad tratada, hecho que seguramente ampliaría el enfoque multicultural y pondría al descubierto otras injusticias, que la misma sociedad occidental europea imponen a los sin papeles, tratándolos como cosas. No obstante, destacamos que lo esencial, desde el punto de vista del guionista, reside en la emoción individual tan hondamente humana que transmiten las dos mujeres representativas de sus comunidades, así como su actitud humana, que no es un aspecto que dependa de la etnia ni de la cultura.

La ciudad cosmopolita se muestra en Biutiful en plena contradicción con el título, saliendo a la luz sus aspectos más pobres, oscuros y marginales, casi irreconocibles, si no fuera por una mirada lejana por la ventana a la Sagrada Familia de Gaudí y, al final, a la idílica playa Barceloneta, cuyo mar expulsa a la superficie los cadáveres chinos. En ese marco, la pobreza es un entorno ineludible, junto con la muerte, para todos los

\footnotetext{
5 Periodista e investigadora etnográfica canadiense, con amplia experiencia laboral en Senegal para UNESCO en programas de desarrollo y protección de los derechos humanos. Véase: http://www.tumblr.com/tagged/senegalese-street-vendors y http://www.justice4migrants.org/
} 
personajes. Si para los ilegales senegaleses o chinos se trata de un hecho asumido por su situación ilegal, que les impide acceder a una vida decente, Uxbal les sigue con humildad por el mismo camino. Por ejemplo, para conseguir un poco de dinero, se ve obligado a vender el nicho de su padre, lo que revela que, para los pobres, ni el descanso en paz dura eternamente. Además, el protagonista vive en un piso feo y repugnante, junto con sus hijos, a los que les tiene que distraer con ingenio para que puedan tragar diariamente la misma comida de mala calidad. Como no tiene medios para cuidar de su salud ni para ir al médico, conmueve y convence su fuerza anímica final, cuando ya ni siquiera se puede poner inyecciones con morfina, y comparte habitación y cuentos imaginarios con sus niños. Aparentemente, sus dones de comunicarse con los difuntos le permiten ganar algo más, que reparte entre las necesidades básicas de la casa y los pobres ilegales que trata de ayudar. No obstante, no muere ni solo ni pobre, porque recibe casualmente una cantidad que le asegura por mucho tiempo la estabilidad de la vivienda y una relativa armonía familiar, gracias a la presencia apacible de la mujer senegalesa. De hecho, la cruel introspección en lo más profundo del cráter de la penuria, tanto física como moral, acaba contrarrestada por el posible triunfo espiritual que implica la digna muerte del protagonista, aunque los efectos de la pobreza excesiva todavía persistan y determinen una dura denuncia social.

Si la película tuviera un prototipo fílmico sobre la interpretación de la enfermedad terminal, los críticos aseguran que sería Ikiru (Living,1952), del reputado Akira Kurosawa, con un argumento considerado tópico. ${ }^{6}$ Se trata de la historia de un funcionario público japonés y su reacción ante la noticia de que tiene cáncer, aprovechada como pretexto para una visión acerca de la condición humana. En cambio, el protagonista de Biutiful no dispone ni del tiempo ni de los privilegios sociales para dejarse llevar por la angustia y la desesperación propias del japonés, ni se embarcará en las cinco etapas definidas por la psiquiatra americana Elisabeth KüblerRoss en el libro On Death and Dying(1969) 7 . En lo que al personaje español se refiere, su enfermedad fatal se convierte en el motor que mueve todas las acciones y le urge ordenar su vida en circunstancias muy difíciles.

$\mathrm{Al}$ ser el cáncer la enfermedad crónica más frecuente de nuestro siglo y la que más muertes causa en los países desarrollados, nos preguntamos si a Uxbal le quedan o no más opciones, aunque tal perspectiva fuera hipotéticamente inverosímil. En este sentido, los consejos espirituales de su mentor apuntan hacia una ley del poder que ya ha decidido su muerte y a la que no puede oponerse y él, como médium, lo sabe muy bien. Es más, como en un anticipo fatalista, el protagonista se percibe a sí mismo atragantado con la Muerte, dentro y fuera; salvo la relación que tiene con sus hijos, todas las demás suyas

${ }^{6}$ V. Philip FRENCH, The Observer, 30, 01/2011. http://www.guardian.co.uk/film/2011/jan/30 /biutiful-review-philip-french-bardem

${ }^{7}$ Se refiere a las etapas de negación, ira, negociación, depresión y aceptación. Véase también su traducción al español. Elisabeth KÜBLER-ROSS, Sobre la muerte y los moribundos, Barcelona, Grijalbo, 1975. E. KÜBLER-ROSS, La muerte: un amanecer, Barcelona, Luciérnaga, 1987. 
están abocadas a la extinción: su oficio secundario de médium con los espíritus de los fallecidos; su matrimonio fracasado; su hermano, perdido por la droga, los trabajos ilegales y los engaños humanos más degradantes; su culpa por el accidente de los chinos y su inútil ayuda a los vendedores africanos. Bastará aludir a pocos elementos, distintos en apariencia, para descubrir el lazo de muertes que palpita y ahoga sus últimos días, tales como sus visitas a los difuntos que no consiguen partir tranquilos, las sórdidas imágenes con la destrucción del nicho en el cementerio, el choque con el cuerpo de su padre embalsamado en el depósito de cadáveres, la alusión al crematorio, la morfina y los pañales que utiliza para calmar sus sufrimientos y para ocultar sus intimidades sangrientas más dolorosas. No obstante, Uxbal logra vencer la corrupción física y mental gracias a una salida al mundo de más allá fantástico, en un paisaje onírico nevado con búhos muertos y mares desaparecidos, todos ellos símbolos de la frontera vida-muerte. En realidad, el protagonista nunca deja entrever su inmenso sufrimiento delante de sus seres queridos. Y si rechaza enérgicamente su enfermedad terminal cuando visita a su mentora espiritual, poco después reconoce su error y hace todo lo humanamente posible para reconciliarse con los espíritus errantes de los recién fallecidos. Poco después, en una discoteca donde buscaba desesperadamente al propio hermano, que le niega cualquier diálogo, confiesa su próxima muerte a una prostituta desconocida, con una sinceridad abrumadora. Estos momentos, los únicos en que se muestra vulnerable, contribuyen a comunicar definitivamente su profunda humanización.

Cabe añadir que el protagonista actúa desde su condición cultural occidental, que ha desacralizado y medicalizado la muerte en sí, quitándole cualquier significado religioso o trascendental. Sin embargo, su ímpetu por solucionar los problemas vitales, sumado a sus cualidades espirituales reinventan una experiencia tanatológica algo distinta, barajándose maneras positivas y negativas de morir. En cuanto a la medicalización contemporánea urbana, la película personifica la enfermedad y la muerte como enemigos. Al tratarse de una enfermedad incurable galopante, el punto de vista médico tiende a centrarse en el tiempo máximo calculado para (sobre)vivir, dejando del lado la disminución de calidad de vida que provocan varios tratamientos, como la quimioterapia. Uxbal elige la morfina y pasar el mayor tiempo posible en casa, fuera de los hospitales y en la compañía de su querida familia, en una lección conmovedora sobre cómo hay que aprender a morir, con mucho sosiego y sin temor.

A propósito de arte o ciencia para aprender a morir, en realidad no se trata de ninguna técnica ni reglas fijas, sostiene, con espíritu juvenil, el mismo Emil Cioran. ${ }^{8}$ En este aspecto, insiste en que hay que integrar la muerte en la vida, lo que es una opción imposible, añade irónicamente, para la mayoría de los mortales, porque carecen de sentido metafísico, o están demasiado sanos. Únicamente la enfermedad y su intimidad dan lugar a experiencias auténticas. Hay mucha literatura y cine ${ }^{9}$ que contemplan la

\footnotetext{
${ }^{8}$ CIOARAN, op. cit., 3.

${ }^{9}$ Difícilmente se podría esbozar una lista exhaustiva de escritores cuya obra y vida han inspirado realizaciones fílmicas excepcionales en torno a la enfermedad, muerte, vejez, pero entre los que
} 
enfermedad como experiencia liberadora, tal como iremos viendo al afrontar distintos conceptos teóricos sobre la muerte en la historia cultural de la humanidad y su relevancia para la interpretación de nuestra película.

\section{Significados de la muerte e intertextualidad}

"Toda nuestra cultura no es más que un inmenso esfuerzo para disociar la vida de la muerte, conjurar la ambivalencia de la muerte en beneficioexclusivo de la reproducción de la vida como valor, y del tiempo como equivalente general."10

Jean Baudrillard

Tomamos como punto de partida la muerte, uno de los ejemplos paradigmáticos esenciales, socialmente hablando. Se sustenta en una gama entera de significados metafísicos, independientemente de la cultura de acogida, urbana o rural, occidental u oriental, antigua o contemporánea, conceptos que perduran en la historia de la humanidad en virtud de dos esferas que confluyen en los momentos antropológicos clave, como el nacimiento y la muerte. La primera esfera representa únicamente al individuo, según una visión holística de cuerpo y alma, con sus creencias íntimas y su funcionalidad vital efímera, mientras que la segunda se refiere a un contexto social determinado, altamente impregnado por ritos y costumbres espirituales, religiosas y etnográficas, así como por el avance histórico y el grado de civilización de la sociedad correspondiente. Es verdad que la muerte es el destino inexorable de todo organismo vivo, pero la coincidencia de las dos esferas en el proceso e interpretación del tránsito hacia el no ser han dado lugar a una hermenéutica diversa. Hay pueblos y culturas que miran el fin de sus días con recelo o pánico, como los países civilizados del Occidente, que ignoran casi por completo el duelo y luto como parte de la vida en sí, tal vez debido a la influencia hedonista y todopoderosa del carpe diem consumista, publicitado ferozmente en los últimos cincuenta años.

A propósito de la interdisciplinaridad inherente a este tipo de análisis, Edgar Morin (1976), uno de los filósofos sociales más reputados, estudia la relación biunívoca entre la actitud frente a la muerte -lo que ulteriormente se ha denominado como ciencia de la muerte- y la conciencia de sí, comprendida como individualidad, lo que remite a las esferas antropológicas antes mencionadas. De hecho, aunque la dimensión sociológica de la muerte se estudia desde hace relativamente poco, la gran poesía y literatura siempre la integraron en sus temas e interpretaciones ontológicas, quizás porque, a diferencia del amor, de la vida o de la naturaleza, es la única experiencia indirecta que impregna a las demás con su toque fundamentalmente disarmónico. ${ }^{11}$ Prolongando la hipótesis de

seguramente ya entraron en la universalidad estarían Edgar Allan Poe, Ernesto Sábato, Max Blecher, Virginia Woolf, Thomas Mann, Reiner Maria Rilke, solo para citar a algunos.

${ }^{10}$ Jean BAUDRILLARD, L'échange symbolique de la mort, Paris, Gallimard, 1976, y su tradución al español, El intercambio simbólico y la muerte, Caracas, Monte Avila Editores, 1993, 103.

${ }^{11}$ Edgar MORIN, L'Homme et la Mort, Paris, Ed. du Seuil. 1976. 
Morin, Philippe Ariès aplica un sistema exegético para la interpretación de elementos tanatológicos literarios, litúrgicos, testamentarios e iconográficos. En L'Homme devant la mort (1985), amplía la visión de la muerte, sumando otros parámetros psicológicos como la fe en la existencia del mal, la fe en la supervivencia y la defensa de la sociedad ante la naturaleza indomada, para analizarlos en su variación y alternancia histórica. ${ }^{12}$ Los modelos propuestos por Ariès, interpretados en nuestra visión determinada también por el ensayo de Irina Petraş ${ }^{13}$ y que aplicaremos a la película Biutiful.

El primer modelo sería la muerte domesticada (la mort apprivoisée), aludiendo al carácter colectivo de la muerte, que consta tanto en las ceremonias rituales públicas, como en la solidaridad social y familiar. Sin embargo, en las sociedades antiguas (desde las arcaicas hasta la antigüedad clásica) la muerte no constituía un drama personal y los impulsos eróticos y tanáticos representan conflictos entre el individuo y el control ejercido por la sociedad y sus instituciones. Como resultado, se imponía la domesticación de esos hechos antropológicos, como escudo de protección contra la naturaleza indomable o contra las aventuras del individuo aislado. De hecho, aun subyugada, la muerte nunca ha sido entendida como un fenómeno neutro. El sufrimiento, el pecado, la desdicha infernal son facetas del Mal, que el Cristianismo explica mediante la doctrina del pecado original.

En nuestro caso, la muerte del protagonista, atentamente escenificada al principio y al final de la película, promueve la idea de que semejante mal es independiente del ser humano, siendo su destino y su fatalidad. Pero los recursos utilizados para reflejar el momento trágico remiten a una imagología fantástica tranquilizante, que derrocha paz y calma redentora, lo que implica un triunfo individual sobre la culpa. Asimismo, ambas comunidades extranjeras de la película se representan como meros colectivos fisiológicos poco espiritualizados, cuyas vidas y muertes ocurren en los mismos espacios y tiempos mezquinos, como verdaderos sepulcros en vida. De alguna manera, Iñárritu logra romper la imagen colectiva gracias a los dos personajes femeninos, Ige y $\mathrm{Li}$, de manera que se convierten en símbolos de la existencia trágica. En efecto, lo trágico vibra esencialmente bajo coordinadas femeninas, pues la mujer es quien sabe mejor qué significa romper su cuerpo para dar a luz y vida a otro ser. Es más, los verdaderos creadores suelen medir su vida también utilizando parámetros femeninos, porque la feminidad significa carencia y fragilidad convertida en creación.

El segundo modelo se denomina la muerte de sí (la mort de soi), que predomina entre los siglos IX y XVI y es el que hace hincapié en el individuo, tal como se desprende de las obras de las élites literarias, de los monjes y clérigos que tratan de distinguirse de la comunidad, tomando conciencia de su propia individualidad. De esta manera, el mundo del más allá se perpetúa mediante la vida del alma y el cuerpo puede

12 Philippe ARIES, L'Home devant la Mort, 2 vol. Paris, Ed. du Seuil, 1985, traducido al español, El hombre ante la muerte Madrid, Taurus, 1987.

${ }^{13}$ Irina PETRAŞ, Ştiinţa Morţii, vol. I, Cluj, Ed. Dacia, 1995, 19-25, así como Ştiinţa Morţii vol. II Piteşti, Paralela 45, 2001, 21-38. 
Significados de la muerte e inmigración en la película Biutiful

morir sin pena. En consecuencia, el anonimato biológico y social se suspende con una dosis de patetismo. Predomina la misma escena de la muerte en la cama, igual que en el modelo anterior. Además, surgen otros elementos ceremoniales entre la cama y la tumba, como las procesiones religiosas, la misa en la iglesia y el cubrimiento del cadáver. ${ }^{14}$ En Biutiful, este modelo solo se refleja en las tormentosas transformaciones de Uxbal, tanto físicas como morales, observadas a lo largo del proceso de declive físico, en contraste con su elevación espiritual. Incluso su muerte se produce en la cama, lo que remite a una visión muy familiar y reconciliadora.

El tercer tipo, la muerte larga y próxima (la mort longue et proche, según una expresión de la Madame de La Fayette) se instaura en el siglo XVI, en contradicción con la época racionalista de los progresos y los desarrollos técnicos que sellan la aparente victoria del hombre sobre la naturaleza. En este período, la muerte provoca curiosidad extrañada y mucho temor, lo que se combina con el erotismo en una mezcla apasionada. También se difunde el miedo a quedar enterrados vivos, de acuerdo con la creencia de que hay estados intermedios reversibles ${ }^{15}$, entre la vida y la muerte. Esta visión no aparece concretamente en la película, salvo en alguna insinuación menor que surge a raíz de la apertura del nicho del padre y el examen del cadáver embalsamado en el depósito, una experiencia que Uxbal vive sin miedo. Además, su padre será quien lo reciba en el reino de los muertos, en un epílogo en el que el amor anula cualquier sentimiento agónico, anunciando el siguiente modelo.

La cuarta modalidad, la muerte del otro o la tuya (la mort de toi) remite a la perspectiva romántica que ya no cree en el destino común y colectivo, pero tampoco en una biografía de la muerte en sí. Como consecuencia, interviene el amor y la expresión de los sentimientos por la muerte de la persona amada. Todo cambia hacia lo privado, hacia la contemplación patética y estetizante de la pérdida del otro, que se compara con el cielo, el mar y el infinito. El compromiso con la hermosura se convierte en el último obstáculo contra lo inefable; ya no se piensa tanto en el infierno, el pecado y el mal como en un destino feliz y paradisíaco, donde todos los seres queridos se vuelven a encontrar. Así pues, el paraíso cristiano y el mundo astral de los espirtistas coinciden aquí en significado, al imaginar un continum mental y afectivo, que solo el amor superior puede alcanzar.

La quinta modalidad, la muerte al revés (la mort inversée) es el modelo moderno del siglo XX, que retoma los elementos del anterior, pero invertidos. La esfera de lo privado persiste, acaso con más fuerza, pero la muerte significa algo sucio, medicalizado; la emoción se ve supeditada a la frialdad de los aparatos que suelen

\footnotetext{
${ }^{14}$ Durante mucho tiempo, la práctica ritual consistía en exponer el cuerpo del fallecido ante las miradas de los demás, desde la cultura bizantina hasta hoy. Creemos que el hecho de cubrirlo ha dado lugar a representaciones ulteriores en las artes macabras que resaltan la degradación corporal, abundantes en la Edad Media.

15 Algunos mencionan la incertidumbre de la medicina sobre el momento exacto de la extinción, lo que sugiere que ni en hoy en día se ha avanzado mucho en la ciencia de la muerte.
} 
rodear al enfermo, a quien se le suele negar la verdad hasta el último instante. Además, la sociedad de consumo, hiperindividualista y carente del antiguo y fuerte sentimiento comunitario, introduce la idea de la muerte vergonzosa, como una muestra de ineficacia personal socialmente intolerable. Lo malo, el infierno o el pecado ya no se aceptan como realidades ineludibles en la existencia humana, sino pasan a considerarse errores sociales.

La película Biutiful no adopta este planteamiento, a pesar de mostrar un amplio panorama de errores de la sociedad contemporánea y sus efectos. Vivimos, en palabras de Bruckner, en un siglo de resignación, aunque el director mexicano plantea una tímida salvación gracias al amor y a la creación humana. ${ }^{16}$

Y entonces ¿cómo hay que afrontar la muerte si el Mal no existe como tal? El mismo Ariès nos da dos respuestas, ninguna de las cuales parece satisfactoria. La primera sería más bien trivial: la muerte es un escándalo que no se puede impedir ni vencer, pero uno puede pretender y hacer creer que no existe. Efectivamente, en las grandes ciudades modernas, el mundo de los muertos se ha reducido al silencio total. El cementerio es un lugar ignorado, rodeado por muros que nadie visita más que una vez al año. Baudrillard asentaba incluso el concepto de "extradición de los muertos", refiriéndose a su aislamiento fuera de la sociedad, y a los solares de la paz convertidos en bloques del tipo cápsula nicho, donde todo se vuelve desolado e irrespirable. Dicho de otra manera, la muerte ya no se puede disolver en el imaginario colectivo y da lugar a la angustia. La segunda variante propuesta por Ariès es la llamada aristocrática, o sea la opción de la indiferencia, del accidente medicalizado, lo que indica que, socialmente, no se reconoce ni admite la muerte como algo natural. Nos preguntamos si tal fenómeno no priva de libertad la misma esencia humana, cuya condición implica la muerte como condición sine qua non. En vez de conclusión, el presente modelo, bajo la máscara de los avances médicos, está instaurando otra vez el pánico a la muerte. La imagen del caos de cables y tubos enganchados a un enfermo terminal es mucho más terrorífica que el esqueleto de las retóricas escatológicas. Si antes la creencia en el Mal llevaba al dominio de la muerte, su desaparición actual del esquema existencial propicia su regreso con mayor fuerza todavía. En la actualidad, la antropología, la psicología y la sociología tratan de conciliar la muerte con la felicidad. ¿Podrán lograrlo en una sociedad que huye del dolor, del sufrimiento y la angustia? No lo creemos posible, al menos mientras la literatura, el cine y los medios de comunicación no digan su última palabra al respecto.

El Libro tibetano de la vida y de la muerte escrito por Sogyal Rinpoche, instituye como noción fundamental la preparación religiosa y espiritual para todos los que están cerca de la muerte. ${ }^{17}$ Aunque la perspectiva de Biutiful se nutre básicamente de conceptos positivistas, regidos por la ciencia y tradición occidentales modernas (sobre todo la judeocristiana, es decir, la europea), el planteamiento artístico y filosófico de Iñárritu

${ }^{16}$ Pascal BRUCKNER, La Mélancolie démocratique: Comment vivre sans ennemis?, Paris, Ed. de Seuil, $1992,78$.

${ }^{17}$ Sogyal RINPOCHE, The Tibetan Book of Living and Dying, San Francisco, Harper Edit, 1992.

Acta Hispanica 20: 91-104, 2015, ISSN: 1416-7263 |101 
orienta el significado hacia más allá de la simple dimensión psicofísica del ser humano. El director imagina una historia vital rodeada de fallecimientos, pero que supera las formas estrictamente biológicas propias de la mera anatomía y sugiere sobre todo la necesidad de instituir socialmente la preparación ante la muerte, con vistas a un "buen morir" sin sentido de la culpa ni cuestiones pendientes. ${ }^{18}$ De hecho, creemos que la encrucijada de culturas y destinos característica de la película, así como de nuestra existencia, favorece una interpretación dinámica que prima la libertad y salvación humanas mediante una espiritualidad que concilia la ciencia y la historia.

A este propósito, el cuadro siguiente retoma los conceptos de la muerte analizados y se los relaciona con algunos elementos narrativos de las culturas china, senegalesa y española, tal como se revelan y confluyen en la película. Como se podrá observar, aunque cada trayectoria es siempre distinta, el mensaje final pone de relieve el encuentro del ser humano con su muerte, en un final libre y trascendente.

Representaciones del binomio vida-muerte en diferentes culturas, según los conceptos de la muerte en la historia de la humanidad, el lugar asignado a la muerte, la modalidad, el mecanismo integrador, la actitud de los personajes ante la vida y la muerte y su interpretación metafísica derivada:

\begin{tabular}{|l|l|l|l|}
\hline $\begin{array}{l}\text { Tipología del } \\
\text { binomio VIDA- } \\
\text { MUERTE }\end{array}$ & $\begin{array}{l}\text { CULTURA } \\
\text { CHINA }\end{array}$ & $\begin{array}{l}\text { CULTURA } \\
\text { SENEGALESA }\end{array}$ & $\begin{array}{l}\text { CULTURA } \\
\text { ESPAÑOLA }\end{array}$ \\
\hline $\begin{array}{l}\text { a) la muerte } \\
\text { domesticada }\end{array}$ & $\begin{array}{l}\text { - perspectiva } \\
\text { colectiva, no } \\
\text { individualizada }\end{array}$ & $\begin{array}{l}\text { - perspectiva } \\
\text { colectiva, prisión } \\
\text { sin muerte, solo } \\
\text { riesgo }\end{array}$ & $\begin{array}{l}\text { - perspectiva } \\
\text { individualizada }\end{array}$ \\
\hline b) la muerte de sí & - no hay sufrimiento & $\begin{array}{l}\text { - brutalidad, } \\
\text { violencia sin } \\
\text { muerte }\end{array}$ & $\begin{array}{l}\text { - hay sufrimiento, más } \\
\text { bien moral que físico }\end{array}$ \\
\hline $\begin{array}{l}\text { c) la muerte larga } \\
\text { y próxima }\end{array}$ & - no existe & - no existe & - no existe \\
\hline $\begin{array}{l}\text { d) la muerte del } \\
\text { otro }\end{array}$ & $\begin{array}{l}\text { - los dos chinos } \\
\text { supervivientes huyen } \\
\text { de responsabilidad y } \\
\text { se deshacen de los } \\
\text { cadáveres }\end{array}$ & $\begin{array}{l}\text { - Ige llora la } \\
\text { ausencia de su } \\
\text { marido }\end{array}$ & $\begin{array}{l}\text { - Uxbal echa de menos a } \\
\text { sus padres muertos }\end{array}$ \\
\hline $\begin{array}{l}\text { e) la muerte al } \\
\text { revés }\end{array}$ & - no existe & - no existe & $\begin{array}{l}\text { - se insinúa, pero en } \\
\text { realidad se propone otro } \\
\text { modelo superior }\end{array}$ \\
\hline f) lugar asignado a & - sótano lúgubre & - posiblemente & - cama \\
\hline
\end{tabular}

${ }^{18}$ Hace poco tiempo, hasta la Organización Mundial de la Salud ha adoptado la consideración espiritual del ser humano y se espera que la próxima definición de salud mental incluya, además de los componentes biológicos, psicológicos, sociales y culturales, también el espiritual. 
Olivia N. Petrescu

\begin{tabular}{|c|c|c|c|}
\hline la muerte & & cárcel & \\
\hline e) modalidad & - asfixia & - no existe & - sueño-viaje \\
\hline $\begin{array}{l}\text { f) mecanismo } \\
\text { integrador }\end{array}$ & $\begin{array}{l}\text { - naturaleza: el } \\
\text { Mediterráneo }\end{array}$ & - indefinido & $\begin{array}{l}\text { - naturaleza: el bosque } \\
\text { nevado donde antes había } \\
\text { agua salada }\end{array}$ \\
\hline $\begin{array}{l}\text { g) creencias, } \\
\text { religiones }\end{array}$ & - indefinido & - indefinido & $\begin{array}{l}\text { - espiritismo, cristianismo } \\
\text { frente a ateismo }\end{array}$ \\
\hline $\begin{array}{l}\text { h) actitud de los } \\
\text { personajes }\end{array}$ & $\begin{array}{l}\text { - en la muerte, la } \\
\text { madre Li y su hijo } \\
\text { están unidos }\end{array}$ & $\begin{array}{l}\text { - en la vida, la } \\
\text { madre Ige y su hijo } \\
\text { están ligados }\end{array}$ & $\begin{array}{l}\text { - Uxbal se encuentra con } \\
\text { su padre y deja a sus hijos } \\
\text { bajo protección ajena }\end{array}$ \\
\hline $\begin{array}{l}\text { j) interpretación } \\
\text { metafísica }\end{array}$ & $\begin{array}{l}\text { - integración en el } \\
\text { ritmo cíclico, } \\
\text { liberación en la } \\
\text { muerte }\end{array}$ & $\begin{array}{l}\text { - destino } \\
\text { suspendido o } \\
\text { abierto; la vida con } \\
\text { los niños por } \\
\text { delante }\end{array}$ & $\begin{array}{l}\text { - elevación espiritual, } \\
\text { sosiego y paz. }\end{array}$ \\
\hline
\end{tabular}

\section{A modo de conclusión}

Lo que se plantea generalmente cualquier commentatio Mortis en la literatura, las artes visuales, las ciencias sociales y la cultura, es profundizar algo más en el irreconciliable obstáculo de la muerte. Hoy por hoy, es verdad que la sociedad occidental muestra una actitud tajante de oposición y rechazo frente a la muerte, lo que conlleva en realidad la negación de la plenitud de la vida.

Respecto a la imagen de la cultura china y africana en la película considerada, ambas con aspecto colectivo muy fuerte, la muerte adquiere, según Lucien Levy-Bruhl ${ }^{19}$ y Mircea Eliade ${ }^{20}$ matices mitico-mágicos, porque la muerte no llega por causas necesariamente naturales, sino que tiene causas comunitarias y místicas y, de ahí, supone finalmente la integración en los ciclos cósmicos. En el caso de los representantes de la cultura senegalesa en la película, no asistimos a ninguna pérdida de vida propiamente dicha y el director encomienda su destino al libre albedrío, lo que implica asumir un nuevo lugar y una nueva vida.

En cuanto a Uxbal, su dedicación secundaria al espiritismo, en su calidad de «protector de la paz de otras almas» podría sugerir conexiones con la doctrina metafísica europea, introducida ya por Platón y continuada con la dimensión trágica y

\footnotetext{
${ }^{19}$ A principios del siglo XX, Lucien Lévy-Bruhl hizo muchas contribuciones en el campo de la filosofía social y antropología relacionadas con la mentalidad primitiva. Sus dos conceptos fundamentales, la representación colectiva y la participación mística, han influido de manera sustancial en la teoría psicológica de C.J. JUNG, Les Racines de La Conscience - Études Sur L' Archétype, Paris, Buchet/Chastel, 1971, 14.

${ }^{20}$ Mircea ELIADE, Occultism, Witchcraft and cultural fashions, Chicago, University of Chicago Press, 1976, en su traducción rumana, Ocultism, vrăjitorie şi mode culturale, Bucureşti, Humanitas, 1997,47-64.
} 
redentora del cristianismo. No obstante, al ser un hombre de una época bastante descreída, el protagonista, al irse viendo abocado a la muerte, se aleja de la corriente existencialista, característica de la Modernidad ${ }^{21}$, e indica, creemos, el cambio radical intervenido en las últimas décadas del siglo XX y comienzos del XXI. En este sentido, la muerte ya no representa una transición, sino más bien un límite. Y a los filósofos les preocupa cada vez menos lo que se halla detrás de ese límite, sino más bien el límite mismo. Igualmente, la muerte en sí se vuelve situación-límite para Uxbal y su fallecimiento no arroja la figura del dualismo platónico cuerpo-alma, sino al hombre viviente en su unidad existencial.

¿En qué sentido es la muerte humana un acontecimiento solo exterior y en qué sentido se la puede considerar una forma interior? queda todavía hoy como tema no solucionado, aunque la trasgresión personal parece innegable. Además, otro rasgo fundamental del siglo XXI consiste en la ampliación cultural de la dimensión hermenéutica de la muerte. En otras palabras, tanto en esta película, como en otras formas de expresión del pensamiento actual, este límite nunca queda como un hecho meramente fisiológico-biológico, sino que siempre aparece relacionado con una interpretación de la vida.

${ }^{21}$ CSEJTEI Dezső, Muerte e inmortalidad en la obra filosófica y literaria de Miguel de Unamuno, Salamanca, Universidad de Salamanca, 2004, 11-23. 